\title{
CAREER PREFERENCES AND PERCEPTIONS OF THE MEDICAL LABOR MARKET AMONG MEXICAN INTERNS
}

\author{
JULio Frenk and RASHID BashshUR \\ Department of Medical Care Organization, School of Public Health, The University of Michigan, \\ Ann Arbor. MI 48109, U.S.A.
}

\begin{abstract}
This paper examines the relationship between choice of career and perception of the medical labor market, as well as the effects of social origin, type of medical school, and place of internship. The data are derived from a survey of interns which was conducted in Mexico during 1978, when a substantial proportion of physicians was unemployed or underemployed.

Career preferences were operationalized in terms of type of activity (general practice or specialty), site (ambulatory or hospital) and institution (public assistance, social security or private). Perceptions of the medical labor market were measured as an 'objective' feasibility perception and a 'subjective' opportunity assessment. Additionally, composite indices of career preferences and perceptions were constructed in order to take account of two integrated career patterns: dominant (or majority preference) vs alternative (or minority preference).

Analysis of the data consistently revealed that perception of the medical labor market had a much stronger impact on preference for alternative than for dominant career patterns. Whereas social origin had no effect on career preference, type of medical school and place of internship exhibited a statistical ineraction with career preference, suggesting that certain structural conditions of the medical school and the teaching hospitals lead to preference for alternative rather than dominant careers.

The implications of the findings are discussed with regard to health manpower policy, to conceptions of rational career choice and to the professional status of medicine in Mexico.
\end{abstract}

\section{THE INTERNSHIP IN MEXICO}

For more than two decades, the internship has represented one of the central elements of medical education in Mexico. In contrast to the American situation, it is part of the formal curriculum of most medical schools. At the same time, the internship in Mexico is characterized by certain inconsistencies that render it a particularly interesting object of study. First, the amount of responsibility for direct patient care by interns varies considerably according to the needs of each hospital and the degree of control by the medical school. Typically, most medical schools exercise limited control over internship training. Second, while medical schools can set broad educational guidelines, the medical care institutions have substantial discretion in determining the clinical services through which interns rotate. Moreover, interns have their own organizations which have at times declared strikes mainly for pay increases. While these organizations are not formally recognized, they do engage in collective bargaining. However, the agreements reached through such negotiations are ratified by the universities and the health care institutions, exclusive of the interns. Thus tension has generated from the dual role of interns as students in medical schools and as workers in health care institutions [1].

A broader issue that might explain the problem addressed in this paper pertains to the conditions of the medical labor market that interns have to face upon graduation. Starting in the early 1970s, the labor market for physicians has been characterized by a marked disequilibrium. Total studènt enrollment increased from 20.127 in 1967 to 41.675 in 1971 [2] and to 80.396 in 1977 [3]. However, due to the slump experienced by the Mexican economy in the 1970s. the expansion in the production of physicians was not accompanied by a corresponding growth in the health care sector [4]. As a result, unemployment began to appear among medical graduates. For example, there were 8000 such graduates in 1978 but only 1800 positions for residency, and it was estimated that the entire health care system, both public and private, could absorb no more than 3000 new physicians per year [5]. Hence, about $40 \%$ of the graduates had to face unemployment or underemployment. Ironically, this occurred while about one-third of the Mexican population was officially estimated not to have access to medical services [6]. Although the increased exportation of oil after 1979 improved the economic situation, leading to an expansion of the health sector, the momentum developed during the previous decade has made it unlikely that the current disequilibrium in the medical labor market will be corrected in the near future. In fact, such disequilibrium could become even more severe under the renewed economic weakness brought about by the world-wide fall in oil prices. Faced with reduced revenues and a growing debt, the Mexican government has already cut public expenditures, in a move that could further deteriorate the ability of the health care institutions to absorb the increased supply of physicians.

\section{THE STUDY OF MEXICAN INTERNS'}

It was from this background that a sample survey of interns was conducted in Mexico during 1978. In addition to describing the content of the internship, the study had the purpose of analyzing the career preferences of interns, as well as their perceptions of the conditions of the medical labor market. 
The sampling scheme consisted of two stages. First. medical schools were stratified by three variables: size (as measured by the number of entering students in 1975), affiliation with a university hospital and sponsorship. It was planned to represent schools in all possible combinations of the three variables, each ordered as a dichotomy. However, some combinations did not occur, and one school that was selected did not participate in the survey while another was unable to complete the arrangements for administering the questionnaire. The final selection consisted of six medical schools. Of these, three were large (more then 500 entering students in 1975) and three small (less than 500 entering students). All large schools were public and only one had a university hospital. Among the small schools, two were public and had a university hospital and one was private and did not have a university hospital.

Subsequently, interns were randomly sampled from these medical schools. Taken together, the six schools had a total of 3820 interns in 1978. Twenty-eight per cent. or 1080 interns, were selected, although the sampling rate was different for each school. A total of 923 interns completed the questionnaire, thereby yielding an overall response rate of $85 \%$, which ranged from a low of $75 \%$ (corresponding to the one private school) to more than $90 \%$ in three schools.

The foregoing discussion implies that the universe from which the sample was drawn and to which our inferences should refer can be conceived of as the total population of interns from the six schools included in the study. Despite the fact that we cannot generalize to the entire population of Mexican interns, it should be noted that, taken together, the six schools of the study comprised 65 per cent of all interns in $1975[7]$.

\section{CONCEPTUAL ORIENTATION}

In a comprehensive review article, Zuckerman [8] has suggested that the main factors presumed to influence career choice within medicine can be classified into three groups: sociodemographic characteristics, personality traits, and institutional for structural) variables. From a different but related perspective. it is possible to propose a developmental mapping of variables that correspond to three time periods: before, during and after medical school.

(a) Before medical school factors related to career preference include social origin, early socialization and family influence.

(b) During medical school factors include professional socialization and faculty influence [9-11], as well as the 'structural' characteristics of the medical school and the teaching hospitals [12].

(c) After medical school factors include perceptions of the medical labor market and the actual conditions of that market $[13,14]$.

In this paper we take the third approach as the point of departure, so that we begin by investigating the extent and manner in which career preferences are influenced by perceptions of the medical labor market among interns who have just completed their internship training. We then move into the analysis of other possible causal factors, such as social origin. type of medical school attended and place of internship.

The reason for centering our analysis of career preference around the effects of interns perceptions of the medical labor market lies in the theoretical and practical importance of this variable. Indeed, such perceptions occupy a fundamental explanatory position in economic theories that posit a rational decision-maker choosing among alternative careers on the basis of 'signals' from the labor market. Similarly. a frequent policy prescription for changing the career choices of medical graduates has been to selectively alter the structure of the market for medical manpower.

Furthermore, it may be noted that the setting in which the present study was conducted was particularly appropriate for analyzing the effects of perception of the medical labor market on career preference. First, the interns included in the study were about to finish their formal medical education and enter the labor market. Hence, they were faced with an imminent need to arrive at a decision about their future careers. Second, the survey was done in Mexico. where there is a clearly defined labor market for physicians. In this country the State owns the majority of health care facilities and employs most of the physicians. Thus, according to one source, $79 \%$ of the 45,532 registered physicians in 1974 were employed by governmental institutions [15], either in public assistance programs for the rural population and the urban indigent or in the social security system for industrial workers and urban employees. While in a private medical care system it is often difficult to differentiate the market for medical services from the market for physician manpower, in a context of public ownership, like the one prevailing in Mexico, there is a well-defined labor market, with an explicit demand for medical manpower which is not simply derived from the demand for medical services. Finally, the Mexican case presents the additional analytical advantage that, in light of the visible conditions of physician unemployment discussed earlier, interns should be motivated to follow the developments in the medical labor market. Therefore, their perceptions of such market should be more clear and explicit than if the market was characterized by equilibrium or by a shortage of physicians.

\section{OPERATIONALIZATION OF VARIABLES}

Career preference, the dependent variable, was operationalized along three dimensions: type of activity (general practice, specialty practice or academic practice), site (ambulatory site, hospital or university), and institution (private, public assistance or social security). Perception of the medical labor market, the first independent variable. was operationalized along the same three dimensions but measured in two ways. The first is an impersonal or 'objective' evaluation of the conditions of the market, regardless of the intern's own chances for employment, herein referred to as feusibility perception. The second is an indication of the intern's views regarding his/her own opportunity to get a job in that particular activity, site and institution. We refer to this latter as opportunity assessment. 


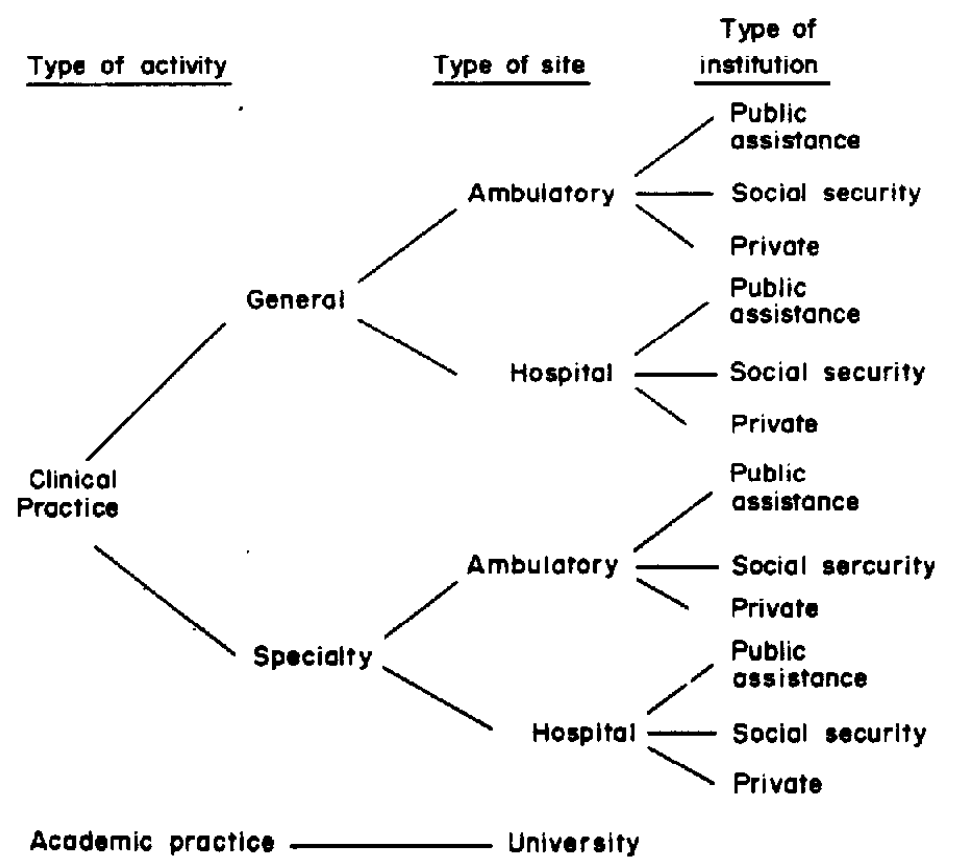

Fig. 1. Career patterns among Mexican interns.

In addition to analyzing these variables separately for each career dimension, we also constructed indices that incorporated all three dimensions simultaneously into integrated career patterns. As presented in Fig. 1, there were twelve such patterns in clinical practice, which will form the focus of our analysis*. In order to reduce these twelve nominal patterns to ordinal indices of career preference and feasibility perception, we took advantage of the empirical gradient regarding how dominant an activity, institution, or site was, as reflected in the interns' own aggregate preferences. As discussed later, specialty practice was the dominant type of activity, in the sense of being preferred by an overwhelming majority of interns. Likewise, hospital was the dominant type of site and social security the dominant type of institution. Therefore, in constructing the indices the pattern, speciality practicehospital-social security, was treated as the 'dominant' category. Similarly, there were two pure alternative patterns: (1) general practice-ambulatory site-public assistance and (2) general practice-ambulatory siteprivate institution. Hence, these two patterns were combined into the 'alternative' category of the indices. Finally, there were some mixed patterns that consisted of various combinations of dominant and alternative types of activity, site, and institution. Those career patterns comprising two alternative and one dominant preference were classified as 'semialternative'. Those patterns consisting of two dominant and one alternative were classified as 'semidominant'.

* As will be shown later, the proportion of interns preferring to work in academic practice or in universities was so low that they have been omitted from the analysis reported in this paper.
Two separate indices were constructed. The first one was based on the career preferences of interns and the second on their feasibility perceptions. Even though the concept of dominance was derived only from the aggregate preferences of interns, the index of feasibility perception was constructured in the same way as the index of career preference, so that the relevant comparisons between these two variables could be carried out and the differential effect of perception on preference could be ascertained. It should be noted that, while the indices in question have the disadvantage of collapsing career patterns in such a way that certain distinctions are lost, they have the advantage of providing summary measures of preference and of feasibility perception that take the three career dimensions simultaneously into account. More important perhaps is the fact that the indices have an empirical basis that avoids a priori assumptions about the stratification of medical practice. They also have potential theoretical implications which deserve further elaboration. For instance, the concept of career dominance can be interpreted as reflecting a prevailing ideological paradigm about the form, content. and organization of medical work. A central research problem concerns the conditions under which such paradigms are developed and the extent to which they conform or clash with the realities of the labor market for physicians. The relationship between the definition of the most preferable modes of medical practice and the external limits imposed by the medical labor market (insofar as these are perceived by future practitioners) is precisely what we attempt to elucidate in this analysis.

With regard to the "subjective' perception of the medical labor market, which we have called 'opportunity assessment", we constructed a Guttman scale with four categories: "very low' (low opportunity assess- 
ment for all three career dimensions), 'low' (low opportunity assessment for type of site and type of institution), 'high' (high opportunity assessment for type of site and type of activity) and 'very high' (high opportunity assessment for all three career dimensions). The scale had a coefficient of reproducibility of $98 \%$, meaning that if we knew only the scale scores we would be able to correctly reproduce $98 \%$ of the original answers to the three items.

In sum, we constructed an index of career preference, an index of feasibility perception, and a scale of opportunity assessment. Each of these measures had four ordered categories. Initial analysis, however, showed essentially the same results when we used the full scale and indices as when we dichotomized each of them at its midpoint*. Hence, for ease of exposition we will present only the analysis for the three dichotomiest.

In addition to the two measures of perception of the medical labor market, three other independent variables will be considered in this article: social origin, type of medical school attended, and place of internship. Social origin was operationalized as a fivepoint index combining father's occupation and father's education. As far as type of medical school is concerned, we classified the six schools of the study according to clusters of structural attributes into two groups: 'exposed' and 'sheltered'. 'Exposed' schools were those that had at least two of the three following characteristics: 1) large entering class (which reflects the existence of external pressures for admission), 2) public sponsorship (which indicates that the school is subject to external control by the State), and 3 ) absence of university hospital (which reflects the need to rely on external clinical facilities). Conversely, a school was classified as 'sheltered' if it presented at least two of the three following structural attributes: 1) small entering class (less than 500), 2) private sponsorship, and 3) presence of a university hospital. As

*For the indices of career preference and of feasibility perception, we collapsed the 'alternative' and 'semialternative' patterns into a single 'alternative' category and the 'semidominant' and 'dominant' patterns into a 'dominant' category. For the scale of opportunity assessment, "very low' and 'low' were combined as 'low' and 'high' and 'very high' as 'high'.

tTables and raw data for the full scale and indices are available on request from the senior author.

+In order to test the stability of the results with respect to this particular grouping of schools, we developed an alternative decision rule, according to which a school was classified as 'exposed' only if it presented all three structural attributes: large, public and no university hospital. Accordingly, the one large public school that had a university hospital (accounting for 128 interns in the sample) became 'sheltered', while the rest of the schools retained their original position. Re-analysis of the data using the alternative decision rule revealed essentially the same results as with the original classification scheme. The only change worth noting was that, under the alternative classification, the relationship between type of medical school attended and career preference was stronger, reaching a Yule's $Q$ value of $-0.36(P<0.001)$. Thus, this exercise showed that our findings were not affected in a meaningful way by the element of arbitrariness that unavoidably accompanies all such classifications. the labels 'exposed" and "sheltered" suggest. this classification attempts to capture the relative premeability of the medical school to external social realities. including the conditions of the labor market for physicians

Finally, place of internship was dichotomized in a manner consistent with the concept of dominance developed for the indices of career preference and of feasibility perception. Thus, those interns that did their internship in a hospital of a social security institution were assigned the code corresponding to a 'dominant' place of internship. Similarly. interns who did their internship in a hospital of the remaining types of institution (public assistance, private, universities, or other) were grouped together in the alternative' category of this variable.

\section{THE 'FINDINGS}

The results will be presented in two parts. The first will focus on the relationship between the two core variables, namely, career preference and perception of the medical labor market. The second part will analyze the effects of the remaining independent variables on career preference, as well as their role in specifying the structural conditions under which perception of the labor market can influence career preference.

The relationship between career preference and perception of the medical labor market

Analysis of separate career dimensions. Initial univariate analysis of each career dimension (i.e. type of activity, of site, and of institution) revealed several interesting trends, as shown in Table 1. First, there was a very marked concentration of responses regarding career preference. Thus, more thàn three-quarters of the interns selected specialty practice as their most preferred activity, while only $17 \%$ preferred general practice and $4 \%$ chose academic practice. For type of site, there was a similarly skewed distribution of responses: $78 \%$ preferred a hospital, $12 \%$ an ambulatory site and $3 \%$ a university. Finally. $57 \%$ of the respondents selected a social security institution, compared to $21 \%$ who chose public assistance and $12 \%$ who preferred to work in the private sector.

When interns were asked to indicate the type of activity, site, and institution where they thought it was most feasible to get a job, their perceptions were remarkably at variance with their stated preferences. In fact, for each of the three career dimensions, feasibility perceptions were ranked in the opposite order as that of preferences. Thus, general practice was considered more feasible than specialty practice and ambulatory sites more feasible than hospitals. Likewise, interns perceived the feasibility of institutions in the following order: private, public assistance and social security. It is also interesting to note that the proportion of 'don't know' responses was markedly higher for each feasibility perception question than for the corresponding dimension of career preference. The most extreme instance was represented by the $29 \%$ of interns who admitted their lack of information regarding employment possibilities by type of institution. Hence, even at a purely descriptive level. univariate distributions revealed general discrepancies 
Table 1. Univariate distributions of career preference, feasibility perception, and opportunity assessment for type of activity, site and institution

\begin{tabular}{|c|c|c|c|c|c|c|}
\hline \multirow{2}{*}{$\begin{array}{c}\text { Career } \\
\text { dimension }\end{array}$} & \multicolumn{2}{|c|}{$\begin{array}{l}\text { Distribution of } \\
\text { career preference* }\end{array}$} & \multicolumn{2}{|c|}{$\begin{array}{c}\text { Distribution of } \\
\text { feasibility perception } \dagger\end{array}$} & \multicolumn{2}{|c|}{$\begin{array}{c}\text { Distribution of } \\
\text { opportunity assessment }\end{array}$} \\
\hline & Category & $\%$ & Category & $\%$ & Category & $\%$ \\
\hline \multirow{8}{*}{$\begin{array}{l}\text { Type of } \\
\text { activity }\end{array}$} & General practice & 17 & General practice & 55 & & \\
\hline & Specialty practice & 77 & Specialty practice & 28 & High & 67 \\
\hline & Academic practice & 4 & Academic practice & 9 & & \\
\hline & Other & 0.3 & Other & 2 & Low & 33 \\
\hline & Don't know & 1 & Don't know & 6 & & \\
\hline & Total & $\overline{100}$ & Total & $\overline{100}$ & Total & $\overline{100}$ \\
\hline & & 903 & $N$ & 903 & $N$ & 879 \\
\hline & Missing data & 20 & Missing data & 20 & Missing data & 44 \\
\hline \multirow{8}{*}{$\begin{array}{l}\text { Type of } \\
\text { site }\end{array}$} & Ambulatory & 12 & Ambulatory & 43 & & \\
\hline & Hospital & 78 & Hospital & 38 & High & 58 \\
\hline & University & 3 & University & 3 & & \\
\hline & Other & 4 & Other & 3 & Low & 42 \\
\hline & Don't know & 3 & Don't know & 13 & & \\
\hline & Total & $\overline{100}$ & Total & $\overline{100}$ & Total & $\overline{100}$ \\
\hline & $N$ & 889 & $N$ & 891 & $N$ & 887 \\
\hline & Missing data & 34 & Missing data & 32 & Missing data & 36 \\
\hline \multirow{8}{*}{$\begin{array}{l}\text { Type of } \\
\text { institution }\end{array}$} & Public assistance & 21 & Public assistance & 23 & & \\
\hline & Social security & 57 & Sacial security & 16 & High & $54^{\circ}$ \\
\hline & Private & 12 & Private & 28 & & \\
\hline & Other & 4 & Other & 4 & Low & 46 \\
\hline & Don't know & 6 & Don't know & 29 & & \\
\hline & Total & $\overline{100}$ & Total & $\overline{100}$ & Total & $\overline{100}$ \\
\hline & $N$ & 889 & $N$ & 875 & $N$ & 876 \\
\hline & Missing data & 34 & Missing data & 48 & Missing data & 47 \\
\hline
\end{tabular}

*The three questions regarding career preference read: "In what type of (activity, site, institution) would you want to work the greatest amount of your time once you have finished all your training as a physician (including residency or post-graduate studies)?

†The three questions regarding feasibility perception read: "In what type of medical (activity, site, institution) do you think it is most feasible to get a job?"

$¥$ The three questions regarding opportunity assessment read: "How do you see your chances of getting a job in the (activity, site, institution) of your choice once you have finished all your training as a physician?"

between what interns preferred and what they perceived to be most feasible in the labor market. The extent and nature of such a discrepancy, of course, can only be established by cross-tabulating the two variables, as will be discussed later on.

Finally, the distributions of answers to the opportunity assessment questions, also shown in Table 1 , indicate that interns as a group had a fairly negative appraisal of their future personal positions in the labor market. Indeed, while a third of them believed that their chances for employment in the activity of choice were low, such proportion reached more than $40^{\circ} \%$ for type of site. Further, almost half of the interns thought that it would be very difficult or impossible to find a job in the preferred institution.

The notion of a discrepancy between career preference and feasibility. perception received further support when we examined contingency tables of these two variables for each separate career dimension. For purposes of brevity, however. these analyses will not be presented here. Suffice it to say that a series of indicators consistently pointed to a differential impact of feasibility perception on career preference, whereby in each career dimension such impact was weakest for the most "popular' or dominant preference (i.e. specialty practice, hospital, and social security institution). Conversely. those interns who preferred the least 'popular' alternatives (i.e. general practice, ambulatory site, and private or public assistance institution) seemed to be much more responsive to their own feasibility perceptions in deciding their career preferences. Further, most of the analysis regarding public assistance revealed response patterns which were more similar to those of private institutions than to those of social security. This seemed to indicate that, as far as the relationship between career preference and perception of the medical labor market is concerned, the split was not between governmental and private institutions. Instead, the contrast occurred between dominant and alternative preferences. It is precisely this relevant distinction that the integrative indices discussed in the previous section attempt to reflect.

Analysis of integrated career patterns. Based on the findings of the analysis of each separate dimension, we constructed the index of career preference, the index of feasibility perception and the Guttman scale of opportunity assessment described earlier. These integrative measures provided a parsimonious way of examining in greater depth the relationship between interns' career choices and their perceptions of the medical labor market. Since they contain the basic insights into the intricacies of that relationship, we will present these findings in greater detail.

Various aspects of the relationship between the integrated patterns of career preference and of feasi- 
Table 2. Relationship between patterns of career preference and patterns of feasibility perception

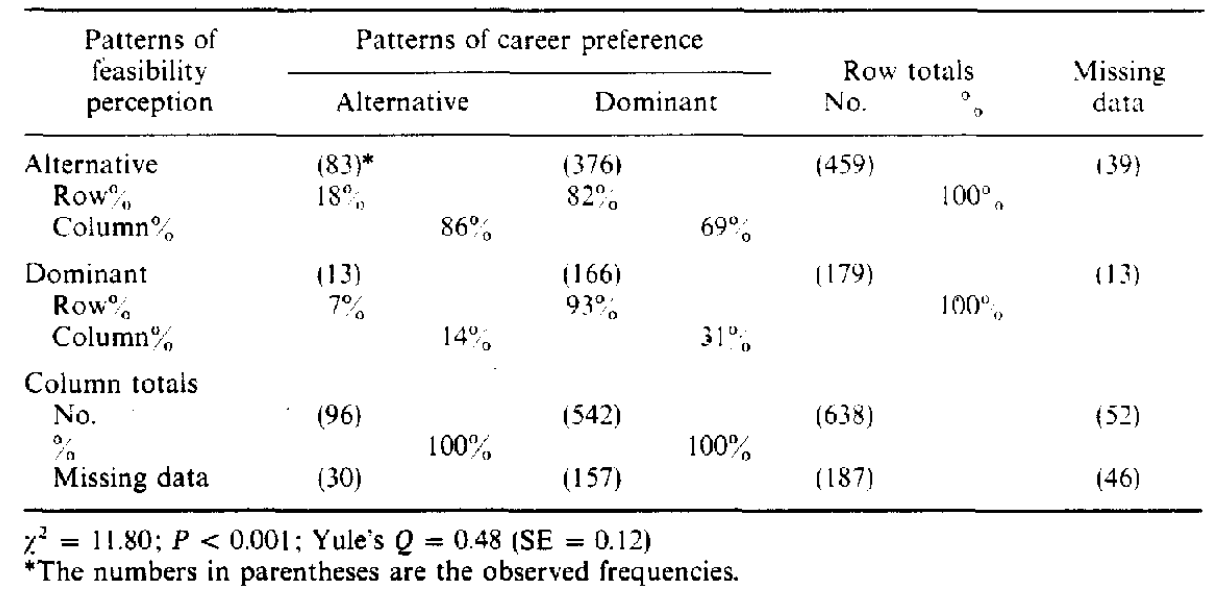

bility perception are shown in Table 2 . The association is highly significant, and it is moderately strong. although, as the size of the standard error suggests, a $95 \%$ confidence interval for Yule's $Q$ is quite wide, ranging from 0.24 to $0.71^{*}$.

The contents of Table 2 make it possible to calculate the proportion of agreement between career preference and feasibility perception by adding the frequencies in the consistent cells, along the main diagonal, and dividing the sum by the number of cases. This procedure reveals that only $39 \%$ of the interns included in the analysis reported a career preference that matched the corresponding feasibility perception. In general terms, this discrepancy reduces our confidence that feasibility perception may represent a major determinant of career preference, since more than $60 \%$ of the interns preferred a career pattern which was not the one where they thought that it was most feasible to get a job.

Apart from this overall measure, Table 2 reveals several differences between the two patterns of career preference. Comparing the column percentages, we find that $86 \%$ of the interns who preferred an alternative career pattern believed that this same type of career was the most feasible one. Such percentage contrasts sharply with the $31 \%$ of interns preferring a dominant career whose preference matched their perception of the 'objective' conditions of the medical labor market. Since the vast majority of interns in fact preferred the dominant pattern, it is not surprising that, overall, there was a discrepancy between preference and feasibility perception.

*The standard error reported in some of the tables provides an indication of the sampling variability of the measure of strength of association, Yule's $Q$ (which is a special case of Goodman-Kruskal gamma when both variables are dichotomous). Using the standard error and a table of the standard normal distribution. it is possible to calculate a $95 \%$ confidence interval for Yule's $Q$, as follows [16]: CI. $=Q \pm(1.96)$ (SE), where C.I. = confidence interval, $Q=$ Yule's $Q$ and $\mathrm{SE}=$ standard error. Of course, if the confidence interval does not include the vilue zero, it is possible to reject the null hypothesis of no association between the two variables involved.
These findings suggest that feasibility perception has a greater influence on the preference for alternative careers than for dominant ones. Indeed, for a full $69 \%$ of the interns preferring a dominant career, it is unlikely that feasibility perception had a very marked impact on their preference, since these interns actually believed that a dominant career was not the most feasible one, and yet they preferred it. In contrast, the much higher proportion of agreement for the alternative career pattern suggests that in this case feasibility perception had a more important influence on preference.

In order to further explore such differential impact, it is necessary to properly treat the index of feasibility perception as the independent variable and compare the row percentages among the two categories of this index at each level of career preference. Thus, Table 2 shows that $18 \%$ of interns who perceived the alternative pattern as most feasible also preferred the alternative pattern, compared to only $7 \%$ of those who perceived the dominant pattern. This represents an absolute difference of 11 percentage points and a relative difference of $61 \%$. Conversely, $93 \%$ of the interns who perceived the dominant pattern as most feasible, vs $82 \%$ of those who perceived the alternative, preferred a career in the dominant pattern. While this is also an 11 percentage point difference, the relative differences now only $12 \%$. Hence, the relationship between feasibility perception and career preference appears to be more marked when such preference is for the alternative than when it is for the dominant pattern.

Analysis of the association between career preference and opportunity assessment provides further insight into this question. If in fact interns who preferred alternative career patterns were more influenced in their choices by their feasibility perceptions than interns who preferred dominant careers, then we would expect the former to have a higher opportunity assessment than the latter. This is because those interns who decided on their preferences according to what they perceived to be objectively' most feasible should consequently express greater confidence that such preferences would be realized in their own personal experience. Hence, the 
Table 3. Relationship between patterns of career preference and levels of opportunity assessment

\begin{tabular}{|c|c|c|c|c|c|}
\hline \multirow{2}{*}{$\begin{array}{c}\text { Levels of } \\
\text { opportunity } \\
\text { assessment }\end{array}$} & \multicolumn{2}{|c|}{ Patterns of career preference } & \multicolumn{2}{|c|}{ Row totals } & \multirow{2}{*}{$\begin{array}{l}\text { Missing } \\
\text { data }\end{array}$} \\
\hline & Alternative & Dominant & No. & $\%$ & \\
\hline $\begin{array}{l}\text { Low } \\
\text { Row \% } \\
\text { Column\% }\end{array}$ & $\begin{array}{l}(31)^{*} \\
10 \%\end{array}$ & $\begin{array}{l}(279) \\
90 \%\end{array}$ & $(310)$ & $100 \%$ & $(28)$ \\
\hline $\begin{array}{l}\text { High } \\
\text { Row } \% \\
\text { Column } \%\end{array}$ & $\begin{array}{l}(83) \\
18 \%\end{array}$ & $\begin{array}{l}(368) \\
82 \%\end{array}$ & $(451)$ & $100 \%$ & (41) \\
\hline $\begin{array}{l}\text { Column totals } \\
\text { No. } \\
\% \\
\text { Missing data }\end{array}$ & $\begin{array}{l}(114) \\
(12)\end{array}$ & $\begin{array}{l}(647) \\
(52)\end{array}$ & $\begin{array}{l}(761) \\
(64)\end{array}$ & & $\begin{array}{l}(69) \\
(29)\end{array}$ \\
\hline
\end{tabular}

$\chi^{2}=10.19 ; P<0.01 ;$ Yule's $Q=-0.34(\mathrm{SE}=0.10)$.

* The numbers in parenthesis are the observed frequencies.

expectation was that there would be a negative association between patterns of career preference and opportunity assessment. Data in Table 3 show this to be the case. While the strength of the association, as indicated by Yule's $Q$, is moderate, it is both significant and in the expected direction. Furthermore, $43 \%$ of the interns who preferred a dominant career, compared to $27 \%$ of those who preferred an alternative, believed that their overall opportunity of getting a job in the career of their choice was low. This represents a difference of 16 percentage points. The results, then, are consistent with the notion of a stronger impact of feasibility perception on preference for alternative careers, which would be reflected in a higher opportunity assessment.

This notion can be tested in a more direct way if we analyze the relationship between patterns of career preference and feasibility perception, stratified by level of opportunity assessment, as shown in Table 4. It is clear that there is a statistical interaction, such that opportunity assessment serves to specify the conditions under which the relationship between feasi-

Table 4. Relationship between career preference and feasibility perception, by level of opportunity assessment

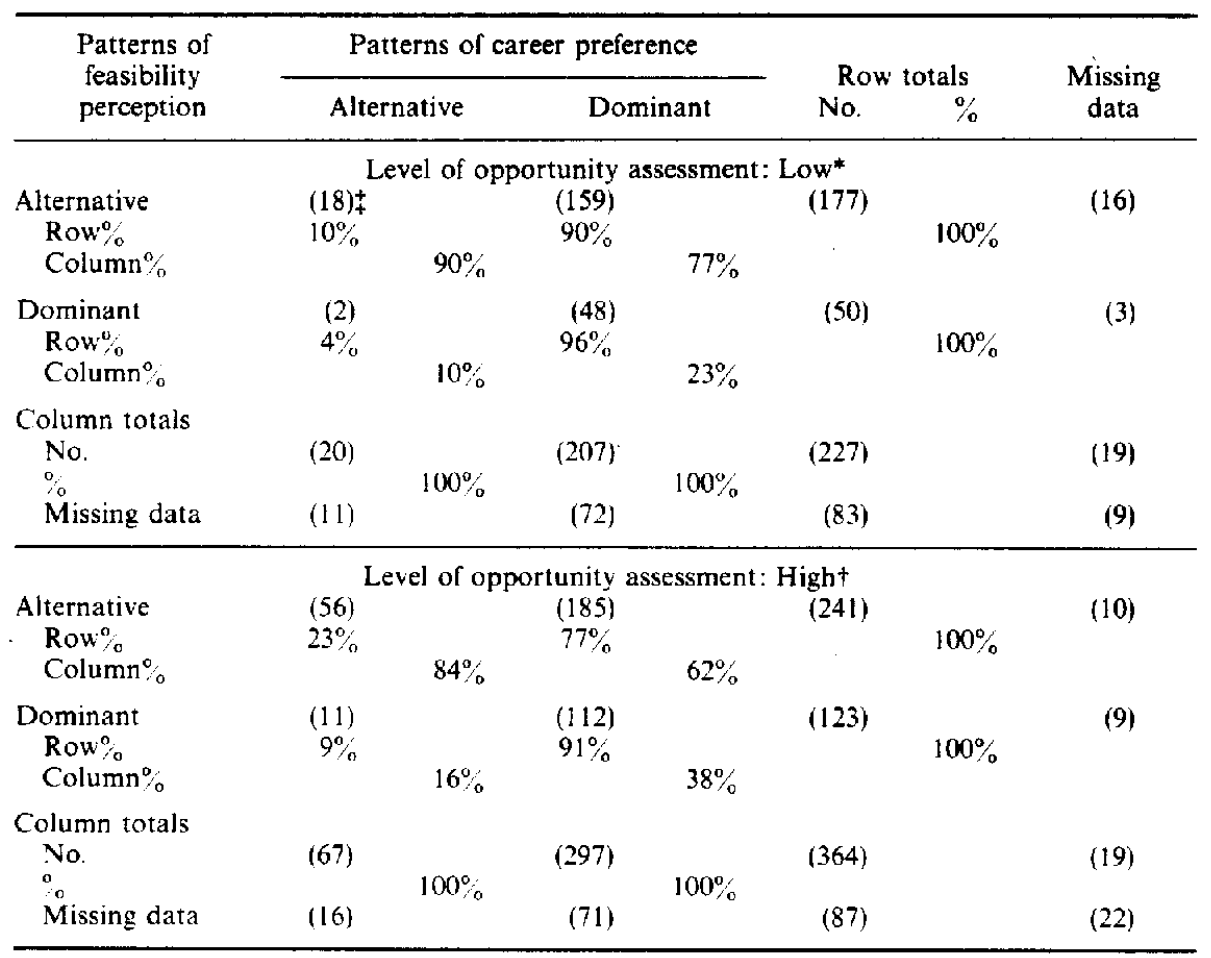

$* y^{2}=1.85: P=0.17:$ Yule's $Q=0.46(\mathrm{SE}=0.30)$

$+\%^{2}=11.08: P<0.001:$ Yule's $Q=0.51$ (SE $=0.13$ ).

${ }_{+}^{+}$The numbers in parentheses are the observed frequencies. 
Table 5. Correlations among career preference and selected independent variablest

\begin{tabular}{|c|c|c|c|c|c|c|}
\hline . & $\begin{array}{c}\text { Career } \\
\text { preference }\end{array}$ & $\begin{array}{l}\text { Feasibility } \\
\text { perception }\end{array}$ & $\begin{array}{c}\text { Opportunity } \\
\text { assessment }\end{array}$ & $\begin{array}{l}\text { Social } \\
\text { origin }\end{array}$ & $\begin{array}{l}\text { Type of } \\
\text { medical } \\
\text { school } \\
\text { attended }\end{array}$ & $\begin{array}{l}\text { Place of } \\
\text { internship }\end{array}$ \\
\hline Career preference & 1.00 & & & & & \\
\hline Feasibility perception & $0.48 * * *$ & 1.00 & & & & \\
\hline Opportunity assessment & $-0.34^{* * *}$ & $0.31 * * *$ & 1.00 & & & \\
\hline Social origin & -0.05 & 0.08 & 0.09 & 1.00 & & \\
\hline $\begin{array}{l}\text { Type of medical } \\
\text { school attended }\end{array}$ & $-0.22^{*}$ & $-0.18^{*}$ & 0.06 & $-0.24^{* * * *}$ & 1.00 & \\
\hline Place of internship & $0.30^{* * *}$ & -0.13 & -0.04 & $-0.10^{*}$ & 0.02 & 1.00 \\
\hline
\end{tabular}

${ }^{*} P<0.05 ; * * P<0.01 ; * * * P<0.001$.

TThe measure of association is Goodman-Kruskal gamma, which is equivalent to Yule's $Q$ when the two variables are dichotomous.

bility perception and career preference occurs, namely, only among interns with a high opportunity assessment. Indeed, when the level of opportunity assessment is held constant at its low level, there is no association between career preference and feasibility perception, since neither the chi square statistic nor Yule's $Q$ are statistically significant. In contrast, when only interns with a high opportunity assessment are included, the relationship is highly significant and slightly stronger than the original zero-order association of Table 2, with Yule's $Q$ now reaching a value of 0.51 . Furthermore, the specific proportions of agreement for each pattern of career preference show consistent differences that can be summarized in the following figures, taken from the column percentages in Table 4:

\begin{tabular}{ccc}
\hline $\begin{array}{c}\% \text { preferring } \\
\text { an alternative } \\
\text { career who also } \\
\text { perceive it as } \\
\text { mosportunity } \\
\text { assessment }\end{array}$ & $\begin{array}{c}\% \text { preferring a } \\
\text { dominant } \\
\text { career who also } \\
\text { perceive it as } \\
\text { most feasible }\end{array}$ \\
\hline Low & 90 & 23 \\
High & 84 & 38 \\
\hline
\end{tabular}

The fact that at both levels of opportunity assessment the proportion of agreement is much higher for alternative than for dominant careers constitutes one further piece of evidence about the differential impact of feasibility perception on career preference. Moreover, when we compare row percentages in order to ascertain the magnitude of the effect of feasibility perception, we find that, while the original effect was summarized as an 11 percentage point difference (Table 2), it is only 6 points in the case of a low level of opportunity assessment, but increases to 14 percentage points when such level is high. In the latter case, the relative difference is considerably higher when the preference is for the alternative $(61 \%)$ than when it is for the dominant pattern $(15 \%)$. Hence, it seems that feasibility perception has an effect on career preference but only when interns considered that their own chances for employment were good, especially for the alternative careers.

In brief, the evidence suggests that perception of the medical labor market influences the preference for alternative but not for dominant careers. The latter are truly dominant, in the sense that a vast majority of interns preferred them. In so doing, these interns were confronting a labor market that, according to their own perceptions, offered vastly divergent alternatives for employment.

The effects of social origin, medical school and place of internship

Having established the essential features of our central object of analysis, namely the relationship between career choice and perception of the medical labor market, the next relevant problem is to identify a set of structural conditions that may distinguish those interns who preferred alternative careers and who were therefore more attentive to their own perceptions of the labor market. In this part of the paper we will explore three such structural variables: social origin. type of medical school and place of internship.

Table 5 presents a summary matrix of GoodmanKruskal gamma values (or, in the case of dichotomous variables, Yule's $Q$ ), which shows that, of the three structural variables, only type of medical school and place of internship were significantly related to career preference. The fact that career preference was independent of social origin is a confirmation of what could be called the 'tabula rasa hypothesis'. This hypothesis, which appears quite frequently in the literature on the sociology of medical education [17], states that medical schools are such powerful socializing institutions that they erase the effects of previous influences, including those of social origin. Thus, a medical school may receive a more or less heterogeneous input (the entering students) but produces a homogeneous output (the graduating students). Once in medical school, students 'forget' their social origin and early socialization to become resocialized as physicians. In the specific area of career choice. the "tabula rasa hypothesis" implies that social origin has no effect on career preference, a proposition that is supported by our data. Still, it should be noted that Table 5 also indicates a significant association between social origin and type of medical school. Since this latter variable was coded in such a way that the 'sheltered' type of school was the 'low' category and the 'exposed' type was the 'high' category, the negative association means that interns from higher 
Table 6. Relationship between career preference and feasibility perception, by type of medical school attended

\begin{tabular}{|c|c|c|c|c|c|c|c|}
\hline \multirow{2}{*}{$\begin{array}{l}\text { Patterns of } \\
\text { feasibility } \\
\text { perception }\end{array}$} & \multicolumn{4}{|c|}{ Patterns of career preference } & \multicolumn{2}{|c|}{ Row totals } & \multirow{2}{*}{$\begin{array}{c}\text { Missing } \\
\text { data }\end{array}$} \\
\hline & Alte & tive & Don & nant & No. & $\%$ & \\
\hline \multicolumn{8}{|c|}{ Type of medical school: 'Sheltered'* } \\
\hline \multirow{2}{*}{$\begin{array}{l}\text { Alternative } \\
\text { Row\% } \\
\text { Column\% }\end{array}$} & $(19)_{+}^{+}$ & & $(135)$ & & (154) & & (12) \\
\hline & $12 \%$ & $79 \%$ & $88 \%$ & $66 \%$ & & $100 \%$ & \\
\hline \multirow{3}{*}{$\begin{array}{l}\text { Dominant } \\
\text { Row } \% \\
\text { Column } \%\end{array}$} & (5) & & $(70)$ & & $(75)$ & & (5) \\
\hline & $7 \%$ & & $93 \%$ & & & $100 \%$ & \\
\hline & & $21 \%$ & & $34 \%$ & & & \\
\hline \multirow{3}{*}{$\begin{array}{l}\text { Column totals } \\
\text { No. } \\
\text { o } \\
\text { Missing data }\end{array}$} & & \multirow[b]{3}{*}{$100 \%$} & & & \multirow{3}{*}{$\begin{array}{r}(229) \\
(67)\end{array}$} & & \multirow{3}{*}{$\begin{array}{l}(17) \\
(10)\end{array}$} \\
\hline & $(24)$ & & $(205)$ & & & & \\
\hline & (11) & & (56) & $100 \%$ & & & \\
\hline \multicolumn{8}{|c|}{ Type of medical school: 'Exposed'† } \\
\hline \multirow{3}{*}{$\begin{array}{l}\text { Alternative } \\
\text { Row } \% \\
\text { Column } \%\end{array}$} & $(64)$ & \multirow[b]{3}{*}{$89 \%$} & $(241)$ & & \multirow[t]{3}{*}{$(305)$} & \multirow{3}{*}{$100 \%$} & \multirow[t]{3}{*}{ (27) } \\
\hline & $21 \%$ & & $79 \%$ & & & & \\
\hline & & & & $72 \%$ & & & \\
\hline \multirow{3}{*}{$\begin{array}{l}\text { Dominant } \\
\text { Row } \% \\
\text { Column } \%\end{array}$} & (8) & & (96) & & \multirow[t]{3}{*}{ (104) } & & \multirow[t]{3}{*}{ (8) } \\
\hline & $8 \%$ & & $92 \%$ & & & $100 \%$ & \\
\hline & & $11 \%$ & & $28 \%$ & & & \\
\hline \multirow{4}{*}{$\begin{array}{l}\text { Column totals } \\
\text { No. } \\
\% \\
\text { Missing data }\end{array}$} & & \multirow{4}{*}{$100 \%$} & & & \multirow{4}{*}{\multicolumn{2}{|c|}{$\begin{array}{l}(409) \\
(120)\end{array}$}} & \multirow{4}{*}{$\begin{array}{l}(35) \\
(36)\end{array}$} \\
\hline & $(72)$ & & $(337)$ & & & & \\
\hline & & & & $100 \%$ & & & \\
\hline & (19) & & (101) & & & & \\
\hline
\end{tabular}

social origin were more likely than those from lower social origin to have attended a 'sheltered' medical school. Hence, although social origin itself did not have a direct effect on career preference. it did influence the type of school attended.

In turn, type of school was significantly associated with career preference, as shown in Table 5. The negative correlation indicates that interns from 'exposed' schools were more likely than those from 'sheltered' schools to prefer an alternative career pattern. Conversely, interns who attended a 'sheltered' medical school were more likely to prefer a dominant career than those who attended an "exposed' school. But not only did type of medical school have a direct effect on career preference. In addition, this variable also served to specify some of the structural conditions under which the basic relationship between career preference and feasibility perception took place. As Table 6 indicates, there is a statistical interaction, whereby that basic relationship is significant only among interns from 'exposed' medical schools and not among those from 'sheltered' schools. This finding tends to validate the notion of the permeability of a medical school to the external conditions of the medical labor market. Indeed, our data suggest that 'exposed' schools have a set of structural characteristics that makes it more likely for their interns to be mindful of their perceptions of the labor market when formulating their career preferences. Further, as mentioned earlier, these interns were also more likely to prefer an alternative career. something that is con- gruent with our previous finding of a stronger impact of feasibility perception on the preference for alternative than for dominant careers.

In this context, place of internship appears to play an interesting role. From Table 5 it is clear that this variable has a significant positive association with career preference. This means that interns who did their internship in an alternative setting were more likely to prefer an. alternative career pattern than interns who did their internship in a dominant type of place, and vice versa. This finding itself provides an indication that, in the course of their internship, future physicians are subject to different structural conditions and experiences which appear to have an impact on their career choices. Perhaps more interesting is the finding that type of school attended and place of internship exhibit a special kind of linkage. As Table 5 indicates, the zero-order relationship between these two variables is not statistically significant. However, the first-order association between career preference, type of medical school, and place of internship is characterized by a clear statistical interaction, as presented in Table 7 . Thus, when only interns from 'sheltered' schools are considered, the value of Yule's $Q$ between place of internship and career preference is only 0.18 , which is not significant, as the size of the standard error suggests. In sharp contrast, among interns from 'exposed' medical schools the association between place of internship and career preference is highly significant, with Yule's $Q$ reaching 0.35 . Likewise, the association between 
Table 7. Percent of interns who prefer the alternative career pattern, by type of medical school attended and place of internship

\begin{tabular}{lccc}
\hline \multirow{2}{*}{$\begin{array}{c}\text { Type of medical } \\
\text { school attended }\end{array}$} & \multicolumn{2}{c}{ Place of internship } & \\
\cline { 2 - 3 } & Alternative & Dominant & Yule's $Q$ \\
\hline Sheltered & $14 \%$ & $10 \%$ & 0.18 \\
& $(129)^{*}$ & $(167)$ & {$[0.17] \dagger$} \\
Exposed & $23 \%$ & $13 \%$ & 0.35 \\
& $(224)$ & $(305)$ & {$[0.10]$} \\
Yule's $Q$ & -0.30 & -0.13 & $N=825$ \\
& {$[0.14]$} & {$[0.15]$} & \\
\hline
\end{tabular}

*The numbers in parentheses are the base $N$ 's for the percentages.

tThe numbers in brackets are the standard errors for Yule's $Q$.

type of medical school attended and career preference is significant only among interns who did their internship in an alternative setting. In this way, the effects of medical school and place of internship on career preference are not simply additive but interactive. As the percentages in Table 7 indicate, the cell with the highest proportion preferring the alternative career pattern (a full $23 \%$ ) is precisely the one corresponding to interns from 'exposed' schools who did their internship in an alternative setting, while the lowest proportion $(10 \%)$ corresponds to interns from a 'sheltered' school and a dominant place of internship.

\section{v1. DISCUSSION}

In this paper we have examined the relationship between career preference and perception of the medical labor market, as well as the effects and interactions of several structural variables. The analysis has consistently revealed the existence of an important discrepancy between preference and perception. Two distinct models of medical practice seem to emerge. The first model--the one that ${ }^{*}$ most interns preferred-includes specialty practice in a hospital of a social security institution. The other model-the one that the majority of interns perceived as most feasible under the current conditions of the medical labor market-includes general practice in an ambulatory site of either a private or a public assistance insti-

* For an analysis of the way in which the assigned textbooks and the curricula of most medical schoois in Mexico reflect the dominant paradigm of scientific medicine, see reference [18]. An analysis of the content and development of such paradigm can be found in Ref. [19].

† For some of the classical sociological definitions and discussions of the professions, see Refs [20-23]. In recent years, several authors have challenged the applicability of the traditional concepts of professionalization to physicians even in developed countries. For example, a lucid analysis of changes in the professional status of American medicine is presented in Ref. [24]. More general innovative conceptualizations about the characteristics of professions and the trends in their development cari be found in Refs [25-27]. tution. The first, dominant, career pattern reflects a highly rationalized mode of practice. one which is based on the division of medical work according to specific specialties, which find its preferred space of action in the concentrated and formalized structure of a hospital, and which fits the institutional framework of a social security system that offers not only job stability but also higher levels of technological and administrative resources. This model encompasses the organizational conditions that are best suited to the practice of the predominant paradigm of scientific medicine as it is taught in most medical schools*. The vast majority of the interns in our sample have apparently internalized such paradigm and expressed it in their career preferences. Yet, they did not perceive either the external conditions of the medical labor market nor their personal opportunities (especially regarding type of institution and site) as being in accordance with their stated preferences.

Whether those perceptions are in fact correct is largely secondary to the basic meaning of the discrepancy. If they truly reflect the interns' future work experience, this would have adverse implications for the job satisfaction and stability of a large segment of Mexican physicians. But beyond this individual level, the tension between career preference and perception of the medical labor market also has important structural implications for the professional status of medicine in Mexico. Most of the sociological literature on the professions has treated medicine as the exemplary expression of professional sovereignty. However, it would seem that the notion of a medical profession vested with the authority and autonomy to control its working conditions is no longer operative in the Mexican context $\dagger$. Instead, the realities of salaried work, of selective demands for manpower by complex organizations and of a labor market characterized by unemployment seem to be defining the conditions of medical practice beyond the preferences of individual physicians.

At the same time, however, those external determinants do not appear to have radically affected the preferences of most interns included in our study. Such a disonance casts doubts over the appropriateness of economic perspective that portray a calculating individual who decides on the career he or she would like to pursue according to an optimization strategy where the conditions of the labor market play a central role. Our results in this respect are consistent with Sloan's findings that differential lifetime-earnings do not explain the choice of specialization over general practice nor of specitic subspecialties $\lfloor 28\rfloor$.

Yet, our evidence also points to the limited circumstances under which perception of the medical labor market apparently exerts a considerable influence on career preference. Indeed, several consistant patterns of differences suggested that the effect of feasibility perception on preference was more marked in the case of the alternative career pattern than in the case of the dominant one. One possible interpretation of this differential impact is that those interns who expressed a preference for alternative. less 'popular', types of activity, institution and site did so to a large extent because they perceived the difficulties of getting a job in the dominant option. 
Furthermore, our analysis has also identified several structural conditions that were associated with a greater likelihood of preferring an alternative career and hence with a greater congruence between preference and perception. In this respect, the role of social origin was limited to influencing the type of medical school an intern would attend. Once this basic selection was done, the effect of type of school on preference seemed to take over. Indeed, interns from 'exposed' schools were not only more likely than those from 'sheltered' schools to prefer alternative careers, but they were also the only ones among whom feasibility perception had an effect on career preference. This finding means either that some schools attract people who, to begin with, pay more attention to their own perceptions of the labor market or, perhaps more likely, that some schools actually are more effective than others in relating to the realities of medical practice and in transmitting them to their students. Moreover, type of medical school interacted with place of internship in the determination of career preference, indicating the existence of a cluster of structural conditions that make the preference for alternative careers more probable. What these findings suggest is the need for an approach to the career choices of future physicians that is more complex than some policy prescriptions have assumed. Indeed, it would seem that, in order to alter those choices, changes in the conditions of the medical labor market-whether intentional or not-will not be sufficient unless they are successfully assimilated into the structures of the medical schools and the teaching hospitals and into the experiences of study, training, work and professional socialization that take place there.

In this way, the present analysis makes it necessary to rethink the validity of common proposals for health manpower policy, of frequent assumptions about the meaning of rationality in career decisions, and of current conceptualizations about the professional status of medicine. It also points to the need for further research into the complex relationships among career preferences, labor market dynamics, and structures of medical education and practice. This kind of research would be a means for understanding some of the basic processes that are shaping the social institution of medical care in a country such as Mexico.

Acknowledgements-The survey of Mexican interns upon which this report is based was conducted at the Xochimilco campus of the Autonomous Metropolitan University of Mexico by Héctor Hernández-Llamas, Ph.D., Lourdes Alvarez-Klein, M.D. and the senior author, with the support of the rector of the University, first Ramón Villarreal, M.D. and later Luis Felipe Bojalil, M.D. Valuable advice at the early. stages of the survey was provided by Juan César Garcia. M.D. of the Pan American Health Organization: Josep Rota. Ph.D.. formerly at the Anahuac University of Mexico: Lucy Reidl. Ph.D., of the National Autonomous University of Mexico: and Rainer Godau. Ph.D. of the College of Mexico. At the University of Michigan, Charles Metzner. Ph.D., Kenneth E. Guire, M.S.. and Frank M. Andrews. Ph.D. were of great help with various aspects of the specific data analysis reported in this paper. We are also indebted to Kay Pierson for her careful preparation of the manuscript. Finally. the National Council of
Science and Technology and the National Academy of Medicine of Mexico provided grants to the survey of Mexican interns. In addition, Julio Frenk has been supported as a Junior Fellow by the Michigan Society of Fellows. The active cooperation of the medical schools included in the study and of all the governmental health care agencies involved is also gratefully acknowledged. While the persons and organizations mentioned above were all essential at different stages of the project, none of them shares any responsibility for the shortcomings of the present paper.

\section{REFERENCES}

1. Frenk J., Hernández-Llamas $\mathbf{H}$. and Alvarez-Klein $\mathbf{L}$. Análisis histórico del internado rotatorio de pregrado en México (Historical analysis of the rotating undergraduate internship in Mexico). Gac. méd. México 119. $77,1983$.

2. Rodriguez M. I. El estudiante de medicina-su distribución en las Américas (The medical student-his distribution in the Americas). Educ, méd. Salud 8, 4, 1974.

3. Dirección General de Servicios Coordinados de Salud Pública en los Estados. Análisis sobre el ejercicio de la medicina en México y sus proyecciones (Analysis and projections of the practice of medicine in Mexico). Unpublished document. 1978.

4. Frenk J., Hernández-Llamas $\mathrm{H}$. and Alvarez-Klein $\mathrm{L}$. El mercado de trabajo médico. 11. Evolución histórica en México (The medical labor market. II. Historical evolution in Mexico). Gac. mèd. México 116, 265, 1980.

5. Rivero $O$. Situación actual de la enseñanza de la medicina (Current situation of medical education). Speech delivered at the ceremony for commemorating the 400 th anniversary of the establishment of the first course of medicine in Mexico. Unpublished document, 1978.

6. Laguna J. Organización de la salud y la seguridad social como factores para el desarrollo social. In Reunion Nacional Sobre el Sector Organizacion y Desarrollo Social. IEPES, México, D.F., 1976.

7. Subsecretaria de Planeación. Educación de Pregrado en Medicina y Enfermeria (Undergraduate Education in Medicine and Nursing), Table 17, pp. 61-62. Secretaria de Salubridad y Asistencia. México, D.F., 1977.

8. Zuckerman H. S. Evaluation of the literature on career choice within medicine. Med. Care Rev. 34, 1079, 1977.

9. Levinson D. J. Medical education and the theory of adult socialization. J. Hith soc. Behat. 8, 253, 1967.

10. Miller S. J. Prescription for Leadership: Training for the Medical Elite. Aldine, Chicago, 1970.

11. Coker R. E., Back K. W., Donnelly T. G. and Miller N. Patterns of influence: Medical school faculty' members and the values and specialty interests of medical students. J. med. Educ. 35, 518, 1960.

12. Zuckerman H. S. Structural factors as determinants of career patterns in medicine. J. med. Educ. 53, 453, 1978.

13. Sloan F. A. Lifetime earnings and physicians' choice of speciality. Ind. Labor Relat. Rev. 24, 47, 1970.

14. Funkenstein D. H. Medical Students, Medical Schools and Society During Five Eras: Factors Affecting the Career Choices of Physicians 1958-1976. Ballinger, Cambridge, MA, 1978.

15. Kumate J., Cañedo L. and Pedrotta O. La Salud de los Mexicanos y la Medicina en México (The Health of Mexicans and Medicine in Mexico), p. 346. Editorial de El Colegio Nacional, México, D.F.. 1977.

16. Statistical Research Laboratory. Elementary Statistics Using MIDAS. p. 196. Statistical Research Laboratory of The University of Michigan, Ann Arbor, 1976.

17. See, for example. Colombotos J. Social origins and ideology of physicians: A study of the effects of early socialization. J. Hith soc. Behat. 10. 16, 1969. 
18. Frenk J. Cuadro clínico de la enseñanza médica mexicana: textos y programas (Clinical picture of Mexican medical education: Textbooks and programs). Nexos. Soc. Ciencia, Lit. 1, 21, 1978.

19. Berliner H. S. A larger perspective on the Flexner Report. Int. J. Hith Serv. 5. 573, 1975.

20. Carr-Saunder A. M. and Wilson P. A. The Professions. Clarendon Press, Oxford, 1933

21. Greenwood E. Attributes of a profession. Social $W k 2$, $45,1957$.

22. Goode W. J. Community within a community: the professions. Am. sociol. Rev. 22. 194, 1957.

23. Freidson E. Profession of Medicine: A Study of the
Sociology of Applied Knowledye. Harper \& Row. New York. 1970

24. Starr P. Medicine and the waning of professional sovereignty. Daedalus, Boston. MA 107. 175. 1978.

25. Johnson T. J. Professions and Power. Macmilan. London, 1972.

26. Haug M. R. Deprofessionalization: an alternative hypothesis for the future. Sociol. Ret. Monogr. 20, 195. 1973.

27. Toren $\mathbf{N}$. Deprofessionalization and its sources: a preliminary analysis. Sociol. $W k$ Occup. 2, 323, 1975.

28. Sloan F. A. op. cit. Ref. [13] 